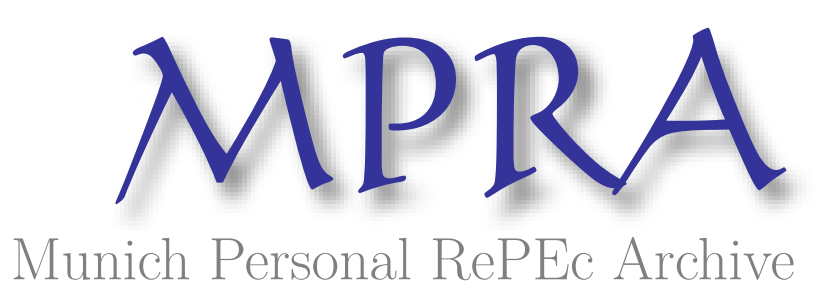

\title{
Does Defensive Medicine Reduce Health Care Spending?
}

\author{
Barkowski, Scott \\ Clemson University
}

1 February 2015

Online at https://mpra.ub.uni-muenchen.de/64318/

MPRA Paper No. 64318, posted 14 May 2015 13:12 UTC 


\title{
Does Defensive Medicine Reduce Health Care Spending?
}

\author{
Scott Barkowski*†
}

February 2015

\begin{abstract}
The medical community often argues that physician fear of legal liability increases health care spending. Theoretically, though, the effect could be positive or negative, and empirical evidence has supported both cases. Previous empirical work, however, has ignored the fact that physicians face risk from industry oversight groups like statelevel medical licensing boards in addition to civil litigation risk. This paper addresses this omission by incorporating previously unused data on punishments by oversight groups against physicians, known as adverse actions, along with malpractice payments data to study state-level health care spending. My analysis suggests that health care spending does not rise in response to higher levels of risk. An increase in adverse actions equal to 16 (the mean, absolute value of year-to-year changes within a state) is found to be associated with statistically significant average annual spending decreases in hospital care and prescription drugs of as much as $0.25 \%$ (nearly $\$ 29$ million) and $0.29 \%$ (almost $\$ 9.3$ million). Malpractice payments were generally estimated to have smaller, statistically insignificant effects.
\end{abstract}

Keywords: defensive medicine; medical malpractice; health care spending; medical licensing

JEL categories: K32, I11, I18, H75, K23

Copyright 2015 by Scott Barkowski. All rights reserved. Short sections of text, not to exceed two paragraphs, may be quoted without explicit permission provided that full credit, including copyright notice, is given to the source.

*John E. Walker Department of Economics, Clemson University, SC, USA, sbarkow@clemson.edu, (864) 656-1892. The substantial majority of the work on this research took place while the author was a doctoral student in the Department of Economics at the University of California, Irvine, CA, USA.

${ }^{\dagger}$ I am indebted to Marianne Bitler, Linda Cohen, David Neumark, and Joanne Song for helpful comments on this research. All errors, however, are mine. 


\section{Introduction}

This paper investigates whether malpractice risk faced by physicians, which originates primarily through the civil litigation system and state-level medical licensing boards, induces changes in the overall cost of health care in the United States. The predominant belief in the medical field is that physicians are overly cautious in their treatment recommendations for patients out of fear of malpractice allegations (Studdert et al., 2005; Bishop et al., 2010; Sirovich et al., 2011; American Medical Association, 2012b). This phenomenon, often referred to as defensive medicine, is thought to cause increased spending on treatments not warranted by medical need. These views have led physicians to call for protection from legal liability in the practice of medicine (Bishop et al., 2010; American Medical Association, 2012a) - calls that have found a receptive audience in the public sector. As of 2006, 26 states had adopted laws limiting malpractice lawsuit damages (Mello, 2006a), and there have been efforts to pass national limits to damages ${ }^{1}$.

The public discourse on the subject of defensive medicine, however, often ignores the fact that the theoretical response by physicians to malpractice risk is ambiguous. The U.S. Congress, Office of Technology Assessment (1994) first formalized this ambiguity by defining positive defensive medicine as when physicians order extra medical services to avoid legal liability, and negative defensive medicine as when they avoid patients or services out of liability fears. In the academic literature, both of these possibilities were incorporated into an economic model by Currie and MacLeod (2008). The uncertainty goes further, though, since even if we know for certain in which direction medical services provided moves in response to risk, the spending result would still be ambiguous. For example, physicians might respond to risk by performing more preventative services - which is positive defensive medicine but which may result in lower spending if more expensive services are prevented ${ }^{2}$. Similarly, avoidance behavior by physicians - negative defensive medicine - could actually increase spending if it leads to more expensive problems in enough of the avoided patients. The empirical literature on the subject of defensive medicine reflects these theoretical ambiguities. Kessler and McClellan (1996) found that laws restricting malpractice damages were associated with decreased spending in heart condition patients, but Currie and MacLeod (2008) found they resulted in increased use of C-section procedures in births. Other authors generally found small effects or no statistically significant evidence for defensive medicine (Dubay et al., 1999, 2001; Baicker et al., 2007; Kim, 2007; Carrier et al., 2010; Thomas et

\footnotetext{
${ }^{1}$ One recent attempt was the Protecting Access to Healthcare Act, H.R. 5, 112th Congress (2012). The bill was passed by the House of Representatives but not the senate.

${ }^{2}$ It is not clear such a scenario would be possible, though, as some research has questioned whether preventative care is any more cost effective than ex-post treatment (e.g., Cohen et al., 2008)
} 
al., 2010). Lakdawalla and Seabury (2012) found defensive medicine had moderate effects on spending growth, but argued these costs were justified by reduced mortality ${ }^{3}$.

My analysis introduces new evidence on the matter by exploiting a previously untapped measure of risk, the state-level frequency of sanctions taken against physicians by industry oversight groups, such as medical boards, Medicare, Medicaid, and hospitals. Known as adverse actions, these sanctions are punishments against physicians for professional misconduct, such as incompetent care or breaking certain types of laws, and are intended to motivate doctors to maintain high quality (Shryock, 1967). Actions taken by state medical boards generally involve restrictions on the physician's license (e.g. probation, suspension, revocation), and actions taken by other organizations are similar conceptually though smaller in scope (e.g. a hospital may suspend clinical privileges). From the perspective of physicians, adverse actions represent a threat that is similar to malpractice litigation risk. Both could result from an alleged medical malpractice incident, and both have potentially large monetary impacts (adverse actions through the inability to practice either temporarily or permanently). Thus, the risk originating from adverse actions could potentially induce defensive medicine and affect spending in the same ways that have been argued for litigation risk.

This paper contributes to the literature by performing the first analysis combining and comparing both of these different types of malpractice risk. Previous work has all focused on the civil litigation risk, leaving a gap in our knowledge regarding the effects of adverse action risk. This is an important discrepancy since the risk posed by adverse actions is one that physicians do not insure against. In contrast, nearly all physicians carry insurance against civil litigation risk (Mello, 2006b), rendering their medical treatment decisions irrelevant to their expected monetary malpractice litigation costs ${ }^{4}$. Some previous authors (e.g. Kessler and McClellan, 1996) have, therefore, suggested that the primary mechanism behind defensive medicine would be indirect or noneconomic costs associated with malpractice litigation, such as reputation effects, stress, or time spent defending against allegations. While this certainly could be the case, a physician facing an adverse action from the state medical board (for example) would face all these same costs in addition to potential economic consequences, since no insurance is available for adverse actions. Thus, if physicians do respond

\footnotetext{
${ }^{3}$ In an international context, Chen and Yang (2014) found evidence of positive defensive medicine in Taiwan.

${ }^{4}$ Malpractice litigation insurance is unlike some other forms of insurance in that it is not experience rated, meaning the claims experiences of individual physicians do not affect the rates they pay for insurance. Instead, malpractice insurance is generally priced based on specialty and geography (Sloan, 1990; Fournier and McInnes, 2001; Mello, 2006b). From the perspective of individual physicians, therefore, malpractice insurance premiums are fixed costs, because their own choices regarding services recommendations have negligible influence on their own insurance rates.
} 
to malpractice litigation risk that they carry insurance for, it would then seem reasonable to expect that they would also respond to risk originating from adverse actions.

Measurement of both malpractice payments and adverse actions is possible through the use data made publicly available by the National Practitioner Data Bank (NPDB). Federal law mandates reporting of both adverse actions and malpractice payments to the NPDB, so this unique government database allows observation of the entire universe (or close to it) of these variables. Using this data, I estimate the effect of changes in the frequency of malpractice payments and adverse actions over a 16 year period on health care expenditures at the state level. I find evidence suggesting that increases in adverse actions against physicians are associated with lower health care expenditures. One additional action taken against a

physician each year is estimated to decrease average state hospital expenditures by as much as 1.6 hundredths of a percent. For spending on prescription drugs, the reduction is as much as 1.8 hundredths of a percent. At the same time, I estimate that malpractice payments generally have much smaller, statistically insignificant effects, a result that is consistent with the argument that physician incentives for responding to malpractice litigation risk are muted due to insurance. To the extent that doctors do in fact respond to this type of risk, though, my results suggest that it also decreases spending since in most cases I estimate coefficients with negative signs.

\section{Empirical investigation}

\section{$2.1 \quad$ Econometric model}

The primary focus of my empirical investigation is to estimate the influence of malpractice risk on state-level health care spending categories. In particular, I estimate linear panel data models of the form:

$$
\ln \left(S P E N D_{s t}\right)=\alpha_{s}+\widetilde{\alpha}_{s} t+\beta_{t}+X_{s t}^{\prime} \gamma+N P D B_{s t}^{\prime} \delta+\epsilon_{s t}
$$

Indexes $s$ and $t$ indicate the state and year, while $\ln \left(S P E N D_{s t}\right)$ represents the natural $\log$ of state-level, real health care expenditures. Column vectors $N P D B_{s t}$ and $X_{s t}$ contain measures of the malpractice risk environment (per the NPDB data) and other control variables, respectively. State fixed-effects are represented by $\alpha_{s}$, and $\widetilde{\alpha}_{s} t$ indicates state-specific, linear time-trends (accounting for long-term, state-specific growth-differences in spending). Year dummy variables are represented by $\beta_{t}$, while $\gamma$ and $\delta$ are column vectors of parameters representing marginal effects on health spending. The $X_{s t}$ vector is comprised of the number of non-federally employed medical doctors in the state, the state population, and the number 
of state residents with private health insurance, Medicaid, and Medicare (all of which are expressed in thousands). Additionally, it contains the number of practicing lawyers in the state (also in thousands), which serves as a measure of the costliness of accessing the state legal system.

The $N P D B_{s t}$ vector is comprised of two yearly count variables: total physicians who received at least one adverse action and total physicians associated with at least one malpractice payout. These variables serve as proxies for the actual probabilities faced by physicians of adverse actions and malpractice payments, and are the primary variables of interest. I construct these measures using data from the NPDB, and so, for brevity, I will at times refer to these jointly as the "NPDB variables". The introduction of adverse actions and malpractice payments as two separate, linear terms is intended to reflect the argument that physicians view both as potentially affecting them via the same mechanism.

I estimate equation (1) for each of four categories of expenditures: hospital care, physician and clinical services, prescription drugs, and other non-durable medical products (the last category being a placebo category). All models are estimated using the within estimator, with state-level, cluster-robust standard errors to account for potential serial cor-

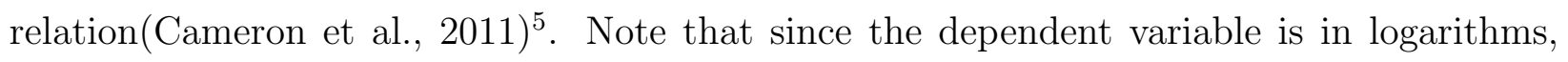
the reported estimates for all coefficients are interpreted as percentage changes in spending due to one unit changes in the independent variables. All reported estimates, though, are multiplied by 100 for presentation purposes in the tables below.

\subsection{Identification}

One of the primary advantages of using the NPDB variables for this type of analysis is that they reflect input from the entire system that oversees physicians, including bureaucratic processes, behaviors of juries and judges, and the litigiousness of the population. The benefits of this as compared to an identification strategy based on changes in tort laws can be seen in a simple example. Suppose a state enacts a damages cap for malpractice lawsuits, but that before the law was passed, there were few allegations of malpractice made in the state in the first place. Upon observing little change in spending, one might conclude that the damages cap had little effect on spending. This conclusion would be faulty, however, because what really happened was there was no real change in the risk level faced by physicians. As there was little enforcement, the change in the law was rendered irrelevant. The NPDB variables, though, would reflect the minimal presence of regulation both before and after the law change, and therefore would more fully account for the risk levels in the state.

\footnotetext{
${ }^{5}$ All regression estimates, including standard errors, were implemented using the "xtreg" command of Stata/SE 12.1 for Windows StataCorp (2011).
} 
Despite this advantage, the use of the NPDB variables as measures of malpractice risk requires careful discussion of the basis for identification. Of first order concern is the threat of endogeneity, since the NPDB variables result from the interaction of the regulatory, litigation, and medical environments in a state. One step I took to address part of these concerns was to rely a frequency count of malpractice payments instead of a measure of the dollar value of payments or other dollar denominated measures like malpractice insurance premiums. This addresses the possibility of bias caused by trends in health care prices and utilization, which obviously play roles in determining health care spending, but that also contribute to the dollar value of malpractice payments and insurance premiums. For malpractice payments, this is because payments are often set to cover some or all of the medical bills of the accusing party. In the case of malpractice insurance premiums, the link comes from the fact that most malpractice payments are actually made by insurers, and premiums are set to help cover the cost of making these payments.

Avoiding dollar based measures of risk only addresses a portion of the endogeneity concerns, though. Another threat is that the NPDB variables may not only reflect pure enforcement, but may also, to some extent, reflect the rate that malpractice occurs in the state. For example, it may be the case that when there is more actual malpractice - perhaps due to generally worse doctors - there are more accusations and stronger cases against physicians, resulting in more observed payments or adverse actions. Basing estimation on measures of regulatory risk that are contaminated in this way could possibly cause misleading results. To reduce the severity of this threat, I include state-level fixed effects in my regressions to account for time-invariant, unobserved heterogeneity at the state-level, including state-specific malpractice rates. Furthermore, I also include state-specific, linear time trends to account for time-varying heterogeneity that occurs in a linear fashion. These steps would still, however, leave the possibility of non-linear time variation in malpractice rates influencing my results. The nature of the NPDB variables, however, provides a solution to this issue. Each malpractice payment and adverse action is the end result of a legal process that begins in year $t_{1}$ with the original incident or injury of the accusing patient. The original incident is possibly a reflection of the malpractice rate since the patient may have received substandard care resulting in injury, but my analysis does not count the incident until the end of the legal process in year $t_{2}$, when a payment is made or an action taken against a physician by an oversight group. These measures are then paired via regression with outcome measures of spending for the corresponding year, $t_{2}$. Thus, the NPDB variables used in my analysis are implicitly lag variables: to the extent that they measure the malpractice rate in the state, they measure it as of $t_{2}-t_{1}$ years before the measurement of the dependent variable in my regressions, state health care spending. In the case of malpractice payments, the 
NPDB data shows that $t_{2}-t_{1}$ is usually quite a long time, as the median payment occurred four years after the incident from which it originated, with the tenth percentile being two years after, and the ninetieth percentile, eight years after. The NPDB does not have the information necessary to determine the time lag for adverse actions, but statistics posted to the website of the Medical Board of California (2010) indicate that the legal process for actions on a physician's license is also quite long, with the sum of the median number of days for the stages of the complaint process exceeding 600 days (and rising) since fiscal year 1999/2000. Category averages for each stage of the medical board legal process also exceed their medians, usually significantly so.

Given this lag aspect of the NPDB variables, the malpractice rate in a state could only influence my estimates if the malpractice rate in year $t_{1}$ has a direct influence on health spending several years after the fact, in year $t_{2}$. Thus, the validity of my estimates relies on the assumption that malpractice rates of years past do not influence spending in the current year. This assumption can be argued to be reasonable because previous research has suggested that the effect of actual malpractice - as in injuries to patients due to medical errors - on health spending is minimal, regardless of the year. A paper from a large study of medical injuries in Utah and Colorado by Thomas et al. (1999) estimated that "adverse events" - injuries caused by medical management, but not necessarily reflecting negligence - accounted for about $4 \%$ of national health expenditures in 1996. Only about half of these costs, though, were due to spending on health care (the rest was lost wages and home production). The amount of adverse events attributable to negligence (i.e. malpractice) was estimated by Brennan et al. (1991) and Thomas et al. (2000) to be on the order of 30\%, bringing the overall estimate of the direct effect of malpractice on health spending to less than $1 \%$ of national health expenditures.

I have presented, therefore, several arguments suggesting that coefficient estimates based on the NPDB variables could be considered credible even if they partially reflect the malpractice rate of the state. These arguments, however, are only necessary in the first place if the NPDB variables do truly reflect the malpractice rate - a possibility that is not supported by previous research. In fact, two large studies of the connection between medical negligence (i.e. malpractice) in American hospitals and malpractice allegations - the first step of the relationship between actual malpractice and adverse actions or malpractice payments - have shown that the link between the two is quite weak. The first study, performed in New York hospitals by Localio et al. (1991), found that a malpractice claim followed an actual example of malpractice only $1.5 \%$ of the time. The second study, by Studdert et al. (2000) and performed in Colorado and Utah hospitals, found a similar estimate of 2.5\%. Furthermore, both studies found that claims of malpractice were frequently made in cases where it was likely no 
malpractice occurred (83\% of claims in the New York sample and $78 \%$ in the Colorado and Utah sample). As a result, the authors of the Colorado and Utah study drew the following conclusions:

"The poor correlation between medical negligence and malpractice claims that was present in New York in 1984 is also present in Utah and Colorado in 1992. Paradoxically, the incidence of negligent adverse events exceeds the incidence of malpractice claims but when a physician is sued, there is a high probability that it will be for rendering nonnegligent care." (p. 250)

Another study, national in scope, by Studdert et al. (2006), focused on the relationship between claims and outcomes of malpractice litigation - the second step of the relationship between malpractice and adverse actions or malpractice payments. Using data on closed claims from medical liability insurers, the authors found that $27 \%$ of malpractice claims regarding incidents in which it was judged that malpractice did actually occur resulted in no payment at all being made to the claimant. Conversely, in cases where no malpractice occurred, payment was still made $28 \%$ of the time. Thus, in cases where a claim is made, the wrong outcome - i.e. a payment made when it should not be or no payment made when it should be - is quite a common occurrence. Overall, once a malpractice accusation has been made, a payment is far from certain. Studdert et al. calculated that $56 \%$ of malpractice claims resulted in a payment being made. Another study by Jena et al. (2011) which had a much larger sample size, however, estimated this rate to be much lower at less than $22 \%{ }^{6}$. The current processes of accusations, negotiations, and legal mechanisms, therefore, imposes a strong filter between the actual occurrence of malpractice and the observation of an outcome in the NPDB. Incidents of actual malpractice rarely result in malpractice claims, and even when claims are made, payment is estimated to take place as little as $22 \%$ of the time. Furthermore, claims and payments are commonly associated with incidents in which no malpractice occurred. These facts suggest that if the NPDB variables reflect the influence of the state's rate of malpractice, it is a very diluted effect.

\subsection{Data}

Equation (1) is estimated using a year-by-state (including Washington DC) panel data set that covers the years 1992 through 2008 and is compiled from several sources. The dependent variable in my regressions is health expenditures by the state of the provider, estimated by the Centers for Medicare and Medicaid Services (2011) as part of their National Health

\footnotetext{
${ }^{6}$ One of the main drawbacks of the work of Jena et al. (2011), though, is that it relies on records of only one insurer. The insurer was a large one that insured physicians in all states.
} 
Expenditure Accounts program. The Consumer Price Index ${ }^{7}$ was used to express these expenditures in 2011 dollars. I use four expenditure categories in my analysis: hospital care, physician and clinical services, prescription drugs, and other non-durable medical products. Hospital care accounts for $37 \%$ of all expenditures and also reflects the highest risk setting 8 . Physician and clinical services reflects $25 \%$ of spending, and, broadly speaking, covers services provided in outpatient settings. The prescription drugs category includes $10 \%$ of total spending and tallies prescription drug sales in retail settings (drugs administered in hospitals or physician offices, and included in hospital or office revenue, are included in the hospital care or physician and clinical services categories). I use the final category, non-durable medical products, for a placebo analysis. This group is much smaller than the other categories at $2.5 \%$ of costs, and is unique in that it covers retail sales of medical products that do not require prescriptions or other physician input for purchase. Additionally, this category reflects almost entirely out-of-pocket spending (Medicare pays a small portion) that is at the consumer's discretion. Examples of products in this category include over-the-counter drugs like cough and allergy medicines and medical sundries such as bandages and thermometers. Legal risks faced by physicians, therefore, would be expected to have no influence on this category of spending 9 .

The NPDB variables are calculated using the Public Use Data File of the NPDB (Health Resources and Services Administration, Bureau of Health Professions, 2011b). By law, the NPDB collects information on all adverse actions taken against and malpractice payments made by (or on behalf of) physicians in the country ${ }^{10}$. Full data collection began at the start of 1992, the first year I use in my analysis. I use the NPDB to count the number of unique physicians associated with malpractice payments and adverse actions by state and year. This includes payments associated with both judgments and settlements, and all types of adverse actions, regardless of the reason given for why the payment was made or adverse action taken (even if it was not necessarily related to medical competence) ${ }^{11}$. However,

\footnotetext{
${ }^{7}$ More precisely, I used the Consumer Price Index for All Urban Consumers: All Items, with the index value for June taken as the value for the whole year (Bureau of Labor Statistics, 2012).

${ }^{8}$ A study of the NPDB by Bishop et al. (2011), using data no longer available to the public, found that roughly half of all malpractice payments originated in a hospital setting, despite that there are almost 30 times more outpatient visits than hospital discharges.

${ }^{9}$ See Centers for Medicare and Medicaid Services (2010) for detailed discussion of the categorization of the National Health Expenditure Accounts.

${ }^{10}$ The National Practitioner Data Bank was established during the presidency of Ronald Reagan by Title IV of Public Law 99-660 (known as the Health Care Quality Improvement Act of 1986), with final regulations found in 45 CFR Part 60 (Health Resources and Services Administration, Bureau of Health Professions, 2001).

${ }^{11}$ There are two justifications for not removing observations on the basis of reason given. First, many records do not have any reason given - $29 \%$ in the case of adverse actions, and $23 \%$ for malpractice payment records. Secondly, and more importantly, it is likely that all actions convey information about the regulatory
} 
two important restrictions are made in order to avoid double counting. For malpractice payments, I exclude payments identified as made by "State Funds", since, according the the NPDB documentation, these payments are usually made only when a payment has also been made by an insurer. In the case of adverse actions, I do not count actions that are identified as modifying previous actions.

The NPDB collects several types of adverse actions, including state licensure actions (e.g. license probation, suspension, or revocation), exclusions from Medicare and Medicaid, and more localized actions such as hospital clinical privileges restrictions. Malpractice payments include those made after trials as part of judgments or jury awards as well as negotiated settlements. The inclusion of settlements is key to the representativeness of the NPDB since they make up a huge portion of the malpractice risk faced by physicians. Judgments and jury awards, in fact, represent less than $3 \%$ of the records in my sample of the NPDB. Thanks to this aspect of the NPDB and the public availability of portions of its data, numerous researchers have made use of it before (e.g., Baicker and Chandra, 2005; Baicker et al., 2007; Bishop et al., 2011).

A natural question to ask when using a dataset like the NPDB is whether it is truly representative of the underlying incidence of malpractice payments and adverse actions. In theory, the law requiring the report of all such events implies that the data should reflect the entire universe, but this could only be true if the required reporting actually takes place. Jena et al. (2011) studied the issue by comparing the malpractice payments data of the NPDB over the period of 1991 to 2005 to data they obtained from a large, national malpractice liability insurer, finding that differences between the two sources were small. No study of the representativeness of the adverse actions data has been performed to my knowledge. However, more than $83 \%$ of records originate from state licensing boards or Medicare/Medicaid, groups which seem likely to report according to the requirements of the law. ${ }^{12}$

Regardless of the extent to which the NPDB reflects the true, underlying incidence of malpractice payments and adverse actions, the NPDB is the appropriate data for my analysis

regime regardless of the basis for the action (e.g. what types of actions lead to adverse actions or payments, and how costly the punishment or payment could be).

${ }^{12}$ The United States General Accounting Office (2000) (GAO) criticized the NPDB for a number of issues, but most notably suggested that it might suffer from under-reporting. This critique was not based on any actual observation of under-reporting, and was undermined in the case of malpractice payments by the laterpublished work of Jena et al. (2011). For adverse actions, the critique was based on the fact that reporting by hospitals was far below the level expected before the creation of the NPDB, but these expectations were necessarily not based on any data source, and may very well have been completely unreasonable. If this type of under-reporting is truly an issue, though, it is likely it would have only minimal impact on measurement of adverse actions in my analysis since my adverse action variable is dominated by the actions of licensing boards and Medicare/Medicaid, organizations that were not subject to the GAO's critique. 
since it is the best available measure of physicians' perceptions of the risk they face. The NPDB represents plays an important role in making information about malpractice payments and adverse actions public, both through the publicly available data and its use by health care organizations during credentialing processes. Thus, the NPDB itself is the object that I need to measure for my analysis - not the underlying incidence of risk that the NPDB intends to measure, rendering the question of representativeness of the NPDB to be somewhat less important in this case.

Besides the NPDB variables, I use figures from the American Bar Association (2012, 2009) for the number of active attorneys in the state. Additionally, I rely on several sources of data for proxies for the production cost of medical services. State level population figures are obtained from Population Division, U.S. Census Bureau (2002, 2009). The number of active medical doctors (excluding those employed by the federal government) comes from the Area Resource File (Health Resources and Services Administration, Bureau of Health Professions, 2011a). Frequency counts for the number of state residents with private insurance, Medicare, or Medicaid, were tabulated by the author from IPUMS CPS data for march of each year (King et al., 2010).

Summary statistics for all the variables used in my analysis can be found in Tables 1 through 3. Table 1 presents statistics on the categories of spending used as dependent variables in terms of millions of (real) dollars. Table 2 presents the same statistics for the natural log of these spending categories, which is the actual form of the variables that are used in my estimations. Table 3 reports statistics for the right hand side variables in my regressions. Note that in this table, the statistics for lawyers and non-federally employed physicians are presented in their true levels, as opposed to their use in my regressions, where the values are in thousands.

\subsection{Results}

Table 5 presents the results of my estimation of equation (1) on my sample of state health expenditures. Each category of health spending has estimates for each of two versions of (1), one with coincidently timed control variables and one in which all controls are lagged one period (that is, $N P D B_{s, t-1}$ and $X_{s, t-1}$ replace their period $t$ versions in equation (1)). The lag version of the model is intended as a check for reverse causality between health care spending and the coincidently timed control variables (especially the non-NPDB control variables, since they do not share the lag feature of the NPDB variables discussed in section $2.2)$.

Focusing first on the hospital care spending category, column (1) presents the model 
with coincident independent variables. I estimate that, on average, one additional physician suffering an adverse action in a year results in a reduction of state hospital expenditures by 1.3 hundredths of a percent, a result that is statistically significant at the $1 \%$ significance level. Relative to the average annual state-level spending on hospital care over my sample period (approximately $\$ 11.5$ billion), this estimate represents a decrease of about $\$ 1.5$ million. For a change equal to the average, year-to-year, within-state change of 16 , this estimate represents a reduction of almost 21 hundredths of a percent, or nearly $\$ 24$ million. In contrast to this result, though, the coefficient for malpractice payments is not statistically significant and is quite close to zero. In fact, the estimate for malpractice payments is more than 225 times smaller than the adverse actions estimate. Given the conventional wisdom in the medical field that fear of malpractice lawsuits is an important determinant of cost, this result is surprising. That said, it is consistent with the view that broad use of malpractice insurance leaves little reason for physicians to alter their behavior out of fear of litigation.

Column (2) presents my estimates for the hospital care regression using lagged values of the right hand side variables. Here, the pattern is nearly identical to column (1), with adverse actions statistically significantly estimated (at the $1 \%$ significance level) to reduce spending by 1.6 hundredths of a percent, a decrease of approximately $\$ 1.8$ million (for a change equal to the average, year-to-year change: decrease of 25.0 hundredths or almost $\$ 29$ million). Malpractice payments are estimated to have a negligible effect that is insignificant at conventional levels. Even the upper bound of the $95 \%$ confidence interval for the malpractice payments coefficient is only $40 \%$ of the magnitude of the estimate for adverse actions. One interesting point to take away from these regressions is that, even though the effect of adverse actions is small relative to the size of hospital care spending in a state, it is large relative to the estimate for the population effect, with estimates for adverse actions in both versions of the model more than doubling the estimates for increasing state population by a thousand residents.

Turning to my estimates for spending on physician and clinical services in columns (3) and (4), I find that adverse actions are again estimated to reduce spending. The estimate for the coincident model is -0.7 hundredths and is not significant, though the lagged model is -1.2 hundredths and is significant at the $10 \%$ level. These coefficient estimates correspond to dollar valued effects of $-\$ 9$ million and $-\$ 15$ million, respectively, for an average-level increase in adverse actions and when evaluated at the category's sample average annual statelevel spending of $\$ 7.8$ billion. Although the point estimates for this category are somewhat smaller than the estimates for the hospital care category, an important reason for the change in significance between categories is that these estimates are less precise, with standard errors increasing by a third and a half for the coincident and lagged models, respectively. 
Comparison with the population effect point estimates for this category still suggests that these estimates have meaningful size, since one additional physician suffering an adverse action results in a change in spending of approximately the same magnitude as increasing the state population by a thousand.

The estimates for malpractice payments for the physician and clinical services category are notably different from the estimates for the other two categories. The coefficient estimate of -0.8 hundredths in the coincidental controls model is statistically significant at the $5 \%$ significance level, a decrease of $0.20 \%$ or nearly $\$ 16$ million for an increase of 26 malpractice payments, the average, year-to-year, within-state change in malpractice payments. The lagged model estimate is similar in magnitude at -0.5 hundredths (-\$0.4 million), though in this case it is not statistically significant. These estimates are considerably larger (in percentage terms) than those for the hospital care and prescription drug categories, and the coincident model result is the only case where I find a statistically significant change in response to malpractice payments. As I will discuss below, however, the regressions I run which include leads for the NPDB variables suggest that this outcome may be influenced by endogeneity bias, which could help explain the inconsistency of these estimates with the other categories.

The next set of regression estimates, for the prescription drug category, can be found in columns (5) and (6) of Table 5. The pattern of estimates in this case is quite similar to that of the hospital care category. The model with coincident regressors estimates a statistically insignificant 1.1 hundredths of a percent reduction due to adverse actions. For an averagelevel change, this corresponds to a reduction of 17 hundredths or $\$ 5.5$ million (relative to the spending category sample average of $\$ 3.2$ billion). The lagged model estimates this same coefficient as -1.8 hundredths $(-0.29 \%$ or $-\$ 9.3$ million for average-level change), which is significant at the $5 \%$ level. These point estimates are nominally close to the estimates from the hospital care category, and, also like the hospital care category, are large relative to the effect of population on spending. In both models in this category, the adverse action estimate is more than four times larger than the population estimate. Thus, the differences in statistical significance between the hospital care category and this one seem to be primarily driven by a drop in the precision of the estimates (standard errors are more than $60 \%$ larger than the hospital care category).

Focusing next on the malpractice payment estimates, I again find that the coefficients are negative, though neither case is statistically significantly different from zero. The estimated reductions of 0.2 and 0.4 hundredths of a percent in columns (5) and (6), respectively, both correspond to drops of approximately $\$ 2$ to $\$ 3$ million in category spending for average-level increases of 26 payments. As in the case of the hospital care category, the magnitudes of 
these estimates are much smaller (at about a quarter in size) than those for the adverse action estimates. This is again consistent with the reasoning that the availability of malpractice insurance reduces physician responsiveness to the likelihood of malpractice payments ${ }^{13}$.

\subsubsection{Placebo analysis}

Regression results for a final spending category, other non-durable medical products, are presented in columns (7) and (8) of Table 5. These results serve as a placebo analysis, since we should not expect to observe an effect of physician risk avoidance behavior on this type of health care spending. If there is no endogeneity bias, we would expect to estimate coefficients for adverse actions and malpractice payments equal to zero. On the other hand, if endogeneity is causing bias (and spurious statistically significant estimates in my main regressions) then we would expect to see significant, non-zero estimates when the placebo category is the dependent variable as well ${ }^{14}$.

This analysis is a credible check of endogeneity to the extent that the dependent variables in my main regressions and the placebo regressions share the same unobserved determinants that may bias coefficient estimates. To that end, state-by-year correlations between other non-durable medical products and the other categories suggest that the groups share similar trends over time. They are 0.94, 0.97, and 0.87 for hospital care, physician and clinical services, and prescription drugs, respectively (0.17, 0.19, and 0.33 for first-differences).

Despite these correlations, the effects of the NPDB variables observed in the main analyses do not appear to carry over in the non-durable medical products case. As columns (7) and (8) show, neither model estimates statistically significant effects for these variables, casting doubt on the possible influence of unobserved factors. Additionally, unlike the estimates for the other categories, which were generally negatively signed for the NPDB variable coefficients, the estimates in this case are positive, suggesting that if there are unobserved factors, they would seem to be working in the opposite direction of the results in the main analyses.

\subsubsection{Checking for endogeneity of the regulatory environment}

Panel A of Table 6 presents results for the estimation of a variation of equation (1) which includes one-period-forward leads for the adverse action and malpractice payments variables

\footnotetext{
${ }^{13}$ The prescription drug category models have noticeably larger estimates for the effect of the physician population on spending. While it is hard to be sure why this differs so much from the other categories, there has been previous research documenting a link between physician geographical concentration and increased sale of prescription drugs, e.g. Bruckner et al. (2012).

${ }^{14}$ Examples of previous uses of placebo analyses can be found in Hamersma and Kim (2009) and Bitler and Carpenter (2012).
} 
(in addition to the coincidently timed versions of those variables). This is intended to address the possibility that the malpractice risk environment itself is a response to conditions in the state. If the NPDB variables are not endogenous, then one would expect that their lead values would estimate as insignificantly different from zero, and estimates of the coincident values of the NPDB variables would be similar to when the models are estimated without leads ${ }^{15}$.

The results for the hospital care and prescription drug spending categories (columns (1) and (3)) have a similar pattern. The coefficient estimates for the coincident version of the adverse actions variable are both statistically significant (1\% level for hospital care and 10\% level for prescription drugs) and have magnitudes that are similar to my main estimates in Table 5. Additionally, the estimates for the adverse actions lead are not significant and are small in comparison to the coincident version estimates. For hospital care, the lead variable estimate is $34 \%$ of the coincident estimate, while for prescription drugs that ratio is $14 \%$. For malpractice payments, neither the coincident nor lead versions have statistically significant estimates in these categories. The estimates are also comparatively small relative to the adverse action estimates, a finding that is consistent with the results of Table 5. For the placebo category, other non-durable medical products, the addition of lead variables does not lead to any interpretive changes. All estimates for this category are statistically insignificant, and magnitudes are similar Table 5 estimates. All of these facts undercut the possibility that the results for these categories found in Table 5 are driven by an endogenous response of the malpractice risk environment to health care spending or other conditions in a state.

The physician and clinical services category, however, has a different story. As is immediately noticeable, the lead variable estimate for malpractice payments is statistically significant (1\% level) and comparatively large at approximately -1 hundredth of a percent. Moreover, the coincident version is not significant and has a much smaller magnitude than the estimates found in Table 5. Additionally, the point estimate for the lead version of the adverse actions is about $50 \%$ larger in terms of magnitude than the coincident version (though neither version of the adverse actions variable has a significant coefficient). These results suggest that there might be some remaining issues with endogeneity in this spending category that my models are not completely eliminating. In the case of malpractice payments, this would seem to explain the statistically significant estimate in Table 5, a result that at first glance seemed out of place due to its dissimilarity with the other categories.

\footnotetext{
${ }^{15}$ Two notable previous uses of this type of strategy to address endogeneity can be found in Gruber and Hanratty (1995) and Friedberg (1998).
} 


\subsubsection{The effect of big states}

To check whether the effects estimated in Table 5 are being driven by the large states, Panel B of Table 6 presents results for the re-estimation of (1) after excluding the largest states in my panel. The excluded states were California, New York, Texas, Florida, Illinois, Pennsylvania, and Ohio, all of which had average populations over the period of my sample of more than 10 million. Each state also exceeded $\$ 66$ billion in average annual health care spending.

The pattern of point estimates is similar to that of Table 5. The most notable magnitude differences are that the adverse action estimate for hospital care spending is about $40 \%$ smaller than it was in Table 5, while the malpractice payments estimates for physician and clinical services and prescription drugs increased by more than $40 \%$ and $300 \%$, respectively. The estimate for malpractice payments in the placebo category, other non durable medical products, also increased in magnitude, rising to 0.9 hundredths, though its adverse action estimate fell to less than a third of the Table 5 estimate. The dropping of observations, though, also resulted in a much lower level of precision for the estimates, so none of the estimates are statistically significant at conventional levels. Nevertheless, the pattern of results seem to suggest that health care spending effects of malpractice risk are not drastically different between the smaller and larger states.

\section{Conclusion}

I have presented evidence suggesting that the practice of defensive medicine may result in decreases in overall average health care spending at the state-level. In particular, I find that rising frequencies of adverse actions against physicians are associated with statistically significant spending decreases in the hospital care and prescription drug categories. My estimates for effects of increasing frequencies of malpractice payments are smaller in comparison to the adverse action estimates and, except for one case, are all statistically insignificant at conventional levels. The one significant estimate indicated a negative effect on spending in the physician and clinical services category, though there is some evidence that there might be endogeneity issues affecting the estimates for this category. These results are particularly interesting in light of the fact that physicians are insured against malpractice litigation risk, but are not insured against adverse actions. Since impediments to their free ability to practice are very costly to physicians, it is not hard to believe that they would be sensitive to changes in the adverse action threat levels. Additionally, finding that malpractice risk

emanating from industry oversight groups is associated with decreases in spending is notable 
given that the medical community has long argued that litigation risk leads to higher health care costs.

There are several mechanisms through which greater fear of punishment or litigation for physicians could result in lower spending levels. Doctors could increase their use of preventative services, leading to fewer cases of more serious (and expensive) illnesses. Alternatively, increased risk could induce physicians to take greater precaution when providing services, leading to fewer errors that require costly additional care. Yet another possibility is doctors may reduce their use of risky services that have low marginal value to the health of the patient (or, more cynically, reduce their use of risky procedures regardless of the value to the health of the patient). The true explanation could even be a combination of these mechanisms and others. This paper, though, makes no attempt to distinguish between mechanisms, and given that previous research has been mixed on the issue of how varying levels of risk influence physician behavior, there is room for additional research on this point. 


\section{References}

American Bar Association, "National Lawyer Population by State 1989 - 2008," 2009. 10

_ , "National Lawyer Population by State 2002 - 2012," 2012. 10

American Medical Association, "H-435.959 Liability Reform," November 2012. 1

_, "Medical Liability Reform - Now!," 2012. 1

Baicker, Katherine and Amitabh Chandra, "The Effect of Malpractice Liability on the Delivery of Health Care," Forum for Health Economics 83 Policy, January 2005, 8 (1), $1-27.9$

_, Elliott S. Fisher, and Amitabh Chandra, "Malpractice Liability Costs And The Practice Of Medicine In The Medicare Program," Health Affairs, May 2007, 26 (3), 841852. 1,9

Bishop, Tara F., Alex D. Federman, and Salomeh Keyhani, "Physicians views on defensive medicine: A national survey," Archives of Internal Medicine, June 2010, 170 (12), 1081-1083. 1

_ , Andrew M. Ryan, and Lawrence P. Casalino, "Paid malpractice claims for adverse events in inpatient and outpatient settings," JAMA: The Journal of the American Medical Association, June 2011, 305 (23), 2427-2431. 8, 9

Bitler, Marianne P. and Christopher S. Carpenter, "Effects of State Cervical Cancer Insurance Mandates on Pap Test Rates," Working Paper July 2012. 13

Brennan, Troyen A., Lucian L. Leape, Nan M. Laird, Liesi Hebert, A. Russell Localio, Ann G. Lawthers, Joseph P. Newhouse, Paul C. Weiler, and Howard H. Hiatt, "Incidence of Adverse Events and Negligence in Hospitalized Patients," New England Journal of Medicine, 1991, 324 (6), 370-376. 6

Bruckner, Tim A., Ashley Hodgson, Chris Brown Mahoney, Brent D. Fulton, Peter Levine, and Richard M. Scheffler, "Health care supply and county-level variation in attention-deficit hyperactivity disorder prescription medications," Pharmacoepidemiology and Drug Safety, 2012, 21 (4), 442-449. 13

Bureau of Labor Statistics, "Consumer Price Index for All Urban Consumers: All Items; Seasonally Adjusted," March 2012. 8

Cameron, A. Colin, Jonah B. Gelbach, and Douglas L. Miller, "Robust Inference With Multiway Clustering," Journal of Business 86 Economic Statistics, April 2011, 29 (2), 238-249. 4

Carrier, Emily R., James D. Reschovsky, Michelle M. Mello, Ralph C. Mayrell, and David Katz, "Physicians Fears Of Malpractice Lawsuits Are Not Assuaged By Tort Reforms," Health Affairs, September 2010, 29 (9), 1585-1592. 1 
Centers for Medicare and Medicaid Services, "National Health Expenditure Accounts: Methodology Paper, 2010; Definitions, Sources, and Methods," 2010. 8

_, "State Health Expenditure Accounts by State of Provider," December 2011. 7

Chen, Brian K. and Chun-Yuh Yang, "Increased Perception of Malpractice Liability and the Practice of Defensive Medicine," Journal of Empirical Legal Studies, 2014, 11 (3), 446-476. 2

Cohen, Joshua T., Peter J. Neumann, and Milton C. Weinstein, "Does Preventive Care Save Money? Health Economics and the Presidential Candidates," New England Journal of Medicine, February 2008, 358 (7), 661-663. 1

Currie, Janet and W. Bentley MacLeod, "First Do No Harm? Tort Reform and Birth Outcomes," The Quarterly Journal of Economics, May 2008, 123 (2), 795-830. 1

Dubay, Lisa, Robert Kaestner, and Timothy Waidmann, "The impact of malpractice fears on cesarean section rates," Journal of Health Economics, August 1999, 18 (4), 491522. 1

_, , and _, "Medical malpractice liability and its effect on prenatal care utilization and infant health," Journal of Health Economics, July 2001, 20 (4), 591-611. 1

Fournier, Gary M. and Melayne Morgan McInnes, "The Case for Experience Rating in Medical Malpractice Insurance: An Empirical Evaluation," The Journal of Risk and Insurance, June 2001, 68 (2), 255-276. 2

Friedberg, Leora, "Did Unilateral Divorce Raise Divorce Rates? Evidence from Panel Data," The American Economic Review, June 1998, 88 (3), 608-627. 14

Gruber, Jonathan and Maria Hanratty, "The Labor-Marker Effects of Introducing National Health Insurance: Evidence From Canada," Journal of Business 8 Economic Statistics, 1995, 13 (2), 163-173. 14

Hamersma, Sarah and Matthew Kim, "The effect of parental Medicaid expansions on job mobility," Journal of Health Economics, July 2009, 28 (4), 761-770. 13

Health Resources and Services Administration, Bureau of Health Professions, "NPDB Guidebook," 2001. 8

_ , "Area Resource File," Technical Report, U.S. Department of Health and Human Services, Rockville, MD 2011. 10

_, "National Practitioner Data Bank Public Use Data File," September 2011. 8

Jena, Anupam B., Seth Seabury, Darius Lakdawalla, and Amitabh Chandra, "Malpractice Risk According to Physician Specialty," New England Journal of Medicine, August 2011, 365 (7), 629-636. 7, 9 
Kessler, Daniel and Mark McClellan, "Do Doctors Practice Defensive Medicine?," The Quarterly Journal of Economics, May 1996, 111 (2), 353 -390. 1, 2

Kim, Beomsoo, "The Impact of Malpractice Risk on the Use of Obstetrics Procedures," The Journal of Legal Studies, June 2007, 36 (S2), S79-S119. 1

King, Miriam, Steven Ruggles, J. Trent Alexander, Sarah Flood, Katie Genadek, Matthew B. Schroeder, Brandon Trampe, and Rebecca Vick, "Integrated Public Use Microdata Series, Current Population Survey: Version 3.0. [Machine-readable database]," 2010. 10

Lakdawalla, Darius N. and Seth A. Seabury, "The welfare effects of medical malpractice liability," International Review of Law and Economics, December 2012, 32 (4), 356-369. 2

Localio, A. Russell, Ann G. Lawthers, Troyen A. Brennan, Nan M. Laird, Liesi E. Hebert, Lynn M. Peterson, Joseph P. Newhouse, Paul C. Weiler, and Howard H. Hiatt, "Relation between Malpractice Claims and Adverse Events Due to Negligence," New England Journal of Medicine, July 1991, 325 (4), 245-251. 6

Medical Board of California, "Average / Median Time To Process Complaints," 2010. 6

Mello, Michelle M., "Medical malpractice: Impact of the crisis and effect of state tort reforms," Research Synthesis Report 10, The Robert Wood Johnson Foundation May 2006. 1

_ , "Understanding Medical Malpractice Insurance: A Primer," Research Synthesis Report 8, The Robert Wood Johnson Foundation January 2006. 2

Population Division, U.S. Census Bureau, "Table CO-EST2001-12-00 - Time Series of Intercensal State Population Estimates: April 1, 1990 to April 1, 2000," Technical Report April 2002. 10

_ , "Table 1. Annual Estimates of the Resident Population for the United States, Regions, States, and Puerto Rico: April 1, 2000 to July 1, 2009 (NST-EST2009-01)," Technical Report December 2009. 10

Shryock, Richard Harrison, Medical Licensing in America, 1650 - 1965, Baltimore, Maryland: The Johns Hopkins Press, 1967. 2

Sirovich, Brenda E., Steven Woloshin, and Lisa M. Schwartz, "Too little? too much? primary care physicians' views on us health care: A brief report," Archives of Internal Medicine, September 2011, 171 (17), 1582-1585. 1

Sloan, Frank A., "Experience Rating: Does It Make Sense for Medical Malpractice Insurance?," The American Economic Review, May 1990, 80 (2), 128-133. 2

StataCorp, "Stata Statistical Software: Release 12," 2011. 4 
Studdert, David M., Eric J. Thomas, Helen R. Burstin, Brett I. W. Zbar, E. John Orav, and Troyan A. Brennan, "Negligent care and malpractice claiming behavior in Utah and Colorado," Medical care, March 2000, 38 (3), 250-260. 6

_, Michelle M. Mello, Atul A. Gawande, Tejal K. Gandhi, Allen Kachalia, Catherine Yoon, Ann Louise Puopolo, and Troyen A. Brennan, "Claims, Errors, and Compensation Payments in Medical Malpractice Litigation," New England Journal of Medicine, May 2006, 354 (19), 2024-2033. 7

_ , _, William M. Sage, Catherine M. DesRoches, Jordon Peugh, Kinga Zapert, and Troyen A. Brennan, "Defensive medicine among high-risk specialist physicians in a volatile malpractice environment," JAMA: The Journal of the American Medical Association, June 2005, 293 (21), 2609-2617. 1

Thomas, Eric J., David M. Studdert, Helen R. Burstin, E. John Orav, Timothy Zeena, Elliott J. Williams, K. Mason Howard, Paul C. Weiler, and Troyen A. Brennan, "Incidence and Types of Adverse Events and Negligent Care in Utah and Colorado," Medical Care, March 2000, 38 (3), 261-271. 6

_, _, Joseph P. Newhouse, Brett I. W. Zbar, K. Mason Howard, Elliot J. Williams, and Troyen A. Brennan, "Costs of medical injuries in Utah and Colorado," Inquiry: a journal of medical care organization, provision and financing, 1999, 36 (3), 255-264. 6

Thomas, J William, Erika C Ziller, and Deborah A Thayer, "Low costs of defensive medicine, small savings from tort reform," Health Affairs, September 2010, 29 (9), 15781584. 1

United States General Accounting Office, "National Practitioner Data Bank: Major Improvements Are Needed to Enhance Data Bank's Reliability," Technical Report GAO01-130, Washington, DC November 2000. 9

U.S. Congress, Office of Technology Assessment, Defensive Medicine and Medical Malpractice number OTA-H-6O2, Washington, DC: U.S. Government Printing Office, July 1994. 1 
Table 1: Dependent variable summary statistics, by expenditure category (Millions of June 2011 dollars)

\begin{tabular}{lcccc}
\hline & Mean & Std. Dev. & Minimum & Maximum \\
\hline Hospital care & 11,523 & 12,556 & 620 & 75,931 \\
Physician \& clinical services & 7,818 & 9,671 & 297 & 67,725 \\
Prescription drugs & 3,159 & 3,745 & 123 & 24,588 \\
Other non-durable medical products & 795 & 925 & 49 & 5,044 \\
All four categories combined & 23,296 & 26,435 & 1,093 & 172,212 \\
\hline Observations & 867 & & & \\
\hline
\end{tabular}

Table 2: Log-scale dependent variable summary statistics, by expenditure category (Log of millions of June 2011 dollars)

\begin{tabular}{lcccc}
\hline & Mean & Std. Dev. & Minimum & Maximum \\
\hline Hospital care & 8.8556 & 1.0191 & 6.4301 & 11.2376 \\
Physician \& clinical services & 8.3948 & 1.0933 & 5.6934 & 11.1232 \\
Prescription drugs & 7.4512 & 1.1617 & 4.8112 & 10.1100 \\
Other non-durable medical products & 6.1145 & 1.1074 & 3.8851 & 8.5259 \\
\hline Observations & 867 & & & \\
\hline
\end{tabular}

Table 3: Independent variable summary statistics

\begin{tabular}{lcccc}
\hline & Mean & Std. Dev. & Minimum & Maximum \\
\hline Physicians suffering adverse actions & 66 & 77 & 0 & 632 \\
Physicians with malpractice payments & 240 & 338 & 10 & 1,838 \\
Practicing lawyers & 19,512 & 26,124 & 1,093 & 150,542 \\
Non-Federally Employed Physicians (M.D.s) & 13,654 & 16,454 & 640 & 95,906 \\
Population ('000s) & 5,515 & 6,130 & 466 & 36,580 \\
Privately insured residents ('000s) & 3,870 & 4,041 & 324 & 23,382 \\
Medicare residents ('000s) & 737 & 780 & 25 & 4,240 \\
Medicaid residents ('000s) & 652 & 880 & 31 & 6,398 \\
\hline Observations & 867 & & & \\
\hline
\end{tabular}


Table 4: Additional summary statistics: absolute values of year-to-year changes

\begin{tabular}{lcccc}
\hline & Mean & Std. Dev. & Minimum & Maximum \\
\hline Physicians suffering adverse actions & 16 & 29 & 0 & 344 \\
Physicians with malpractice payments & 26 & 43 & 0 & 410 \\
\hline Observations & 816 & & \\
\hline
\end{tabular}


Table 5: Regression results by health care spending category

Dependent variable is the log of category health care spending

All estimates are multiplied by 10,000 (i.e. they are expressed in hundredths of a percent)

\begin{tabular}{|c|c|c|c|c|c|c|c|c|}
\hline & \multicolumn{2}{|c|}{$\begin{array}{l}\text { Hospital } \\
\text { Care }\end{array}$} & \multicolumn{2}{|c|}{$\begin{array}{c}\text { Physician \& Clinical } \\
\text { Services }\end{array}$} & \multicolumn{2}{|c|}{$\begin{array}{l}\text { Prescription } \\
\text { Drugs }\end{array}$} & \multicolumn{2}{|c|}{$\begin{array}{l}\text { Other Non-Durable } \\
\text { Medical Products } \\
\text { (Placebo Category) }\end{array}$} \\
\hline & $(1)$ & $(2)$ & $(3)$ & $(4)$ & $(5)$ & $(6)$ & $(7)$ & (8) \\
\hline $\begin{array}{l}\text { Timing of regressors } \\
\text { (relative to dependent variable) }\end{array}$ & Coincident & Lagged & Coincident & Lagged & Coincident & Lagged & Coincident & Lagged \\
\hline Physicians suffering adverse actions & $\begin{array}{c}-1.295^{* * *} \\
(0.461)\end{array}$ & $\begin{array}{c}-1.561^{* * *} \\
(0.463)\end{array}$ & $\begin{array}{l}-0.715 \\
(0.615)\end{array}$ & $\begin{array}{l}-1.202^{*} \\
(0.702)\end{array}$ & $\begin{array}{l}-1.083 \\
(0.756)\end{array}$ & $\begin{array}{c}-1.840^{* *} \\
(0.746)\end{array}$ & $\begin{array}{c}0.889 \\
(0.939)\end{array}$ & $\begin{array}{c}0.778 \\
(0.920)\end{array}$ \\
\hline Physicians with malpractice payments & $\begin{array}{c}0.00574 \\
(0.303)\end{array}$ & $\begin{array}{l}0.0195 \\
(0.305)\end{array}$ & $\begin{array}{c}-0.779^{* *} \\
(0.384)\end{array}$ & $\begin{array}{l}-0.528 \\
(0.434)\end{array}$ & $\begin{array}{l}-0.249 \\
(0.618)\end{array}$ & $\begin{array}{l}-0.392 \\
(0.558)\end{array}$ & $\begin{array}{c}0.142 \\
(0.929)\end{array}$ & $\begin{array}{l}0.0747 \\
(0.808)\end{array}$ \\
\hline Practicing lawyers ('000s) & $\begin{array}{l}-6.617 \\
(6.089)\end{array}$ & $\begin{array}{c}1.343 \\
(6.685)\end{array}$ & $\begin{array}{l}-12.51 \\
(9.915)\end{array}$ & $\begin{array}{l}-10.23 \\
(9.346)\end{array}$ & $\begin{array}{c}30.13^{* * *} \\
(9.906)\end{array}$ & $\begin{array}{l}17.81^{* *} \\
(7.926)\end{array}$ & $\begin{array}{c}27.19^{* * *} \\
(8.937)\end{array}$ & $\begin{array}{r}27.70^{* * *} \\
(8.344)\end{array}$ \\
\hline Non-federally employed physicians ('000s) & $\begin{array}{c}77.32 \\
(59.33)\end{array}$ & $\begin{array}{l}42.96 \\
(55.19)\end{array}$ & $\begin{array}{c}8.317 \\
(59.63)\end{array}$ & $\begin{array}{c}16.39 \\
(63.96)\end{array}$ & $\begin{array}{c}277.0^{* * *} \\
(87.70)\end{array}$ & $\begin{array}{c}224.6^{* * *} \\
(74.99)\end{array}$ & $\begin{array}{l}-14.38 \\
(85.61)\end{array}$ & $\begin{array}{l}-4.511 \\
(89.19)\end{array}$ \\
\hline Population ('000s) & $\begin{array}{l}0.600^{*} \\
(0.324)\end{array}$ & $\begin{array}{l}0.565^{* *} \\
(0.274)\end{array}$ & $\begin{array}{l}-0.873 \\
(0.874)\end{array}$ & $\begin{array}{l}-1.049 \\
(0.855)\end{array}$ & $\begin{array}{c}0.267 \\
(0.864)\end{array}$ & $\begin{array}{c}0.417 \\
(0.731)\end{array}$ & $\begin{array}{c}0.00400 \\
(0.880)\end{array}$ & $\begin{array}{l}-0.603 \\
(0.744)\end{array}$ \\
\hline Privately insured residents ('000s) & $\begin{array}{l}-0.0330 \\
(0.0990)\end{array}$ & $\begin{array}{c}0.0920 \\
(0.0903)\end{array}$ & $\begin{array}{l}-0.0355 \\
(0.134)\end{array}$ & $\begin{array}{l}0.0700 \\
(0.164)\end{array}$ & $\begin{array}{l}0.241^{*} \\
(0.131)\end{array}$ & $\begin{array}{l}0.277^{*} \\
(0.149)\end{array}$ & $\begin{array}{c}0.331 \\
(0.210)\end{array}$ & $\begin{array}{c}0.273 \\
(0.214)\end{array}$ \\
\hline Medicare insured residents ('000s) & $\begin{array}{l}0.0745 \\
(0.207)\end{array}$ & $\begin{array}{l}0.0145 \\
(0.255)\end{array}$ & $\begin{array}{l}-0.262 \\
(0.346)\end{array}$ & $\begin{array}{c}-0.184 \\
(0.314)\end{array}$ & $\begin{array}{l}0.0743 \\
(0.362)\end{array}$ & $\begin{array}{c}0.343 \\
(0.436)\end{array}$ & $\begin{array}{l}0.0955 \\
(0.469)\end{array}$ & $\begin{array}{l}-0.122 \\
(0.525)\end{array}$ \\
\hline Medicaid insured residents ('000s) & $\begin{array}{c}0.193 \\
(0.132)\end{array}$ & $\begin{array}{l}-0.0461 \\
(0.148) \\
\end{array}$ & $\begin{array}{l}0.370^{*} \\
(0.203)\end{array}$ & $\begin{array}{c}0.544^{* * *} \\
(0.197)\end{array}$ & $\begin{array}{c}0.293 \\
(0.234)\end{array}$ & $\begin{array}{l}-0.109 \\
(0.251)\end{array}$ & $\begin{array}{c}0.101 \\
(0.284)\end{array}$ & $\begin{array}{c}0.208 \\
(0.278) \\
\end{array}$ \\
\hline $\begin{array}{l}\text { Observations } \\
\text { Adjusted } R^{2}\end{array}$ & $\begin{array}{c}867 \\
0.978\end{array}$ & $\begin{array}{c}816 \\
0.979\end{array}$ & $\begin{array}{c}867 \\
0.961\end{array}$ & $\begin{array}{c}816 \\
0.959\end{array}$ & $\begin{array}{c}867 \\
0.991\end{array}$ & $\begin{array}{c}816 \\
0.990\end{array}$ & $\begin{array}{c}867 \\
0.837\end{array}$ & $\begin{array}{c}816 \\
0.830\end{array}$ \\
\hline
\end{tabular}

Notes: Standard errors (clustered at state-level) in parentheses. Conventional levels of statistical significance (for two-tailed tests) indicated as ${ }^{*} p<0.1,{ }^{* *} p<0.05$, ${ }_{* * *} p<0.01$. All regressions also included year and state fixed effects and state-specific, linear time-trends that are not reported. 
Table 6: Robustness checks of regression results

Dependent variable is the log of category health care spending

All estimates are multiplied by 10,000 (i.e. they are expressed in hundredths of a percent)

\begin{tabular}{|c|c|c|c|c|c|c|c|c|}
\hline & \multicolumn{4}{|c|}{ Panel A: Including Leads } & \multicolumn{4}{|c|}{ Panel B: Excluding Big States } \\
\hline & $\begin{array}{c}\text { Hospital } \\
\text { Care } \\
(1)\end{array}$ & $\begin{array}{c}\text { Physician } \\
\& \\
\text { Clinical } \\
\text { Services } \\
(2)\end{array}$ & $\begin{array}{c}\text { Prescription } \\
\text { Drugs } \\
(3)\end{array}$ & $\begin{array}{c}\text { Other Non- } \\
\text { Durable } \\
\text { Medical } \\
\text { Products } \\
\text { (Placebo } \\
\text { Category) } \\
(4)\end{array}$ & $\begin{array}{c}\text { Hospital } \\
\text { Care } \\
(5)\end{array}$ & $\begin{array}{c}\text { Physician } \\
\& \\
\text { Clinical } \\
\text { Services } \\
(6)\end{array}$ & $\begin{array}{c}\text { Prescription } \\
\text { Drugs } \\
(7)\end{array}$ & $\begin{array}{c}\text { Other Non- } \\
\text { Durable } \\
\text { Medical } \\
\text { Products } \\
\text { (Placebo } \\
\text { Category) } \\
(8)\end{array}$ \\
\hline Physicians suffering adverse actions & $\begin{array}{c}-1.107^{* *} \\
(0.431)\end{array}$ & $\begin{array}{l}-0.398 \\
(0.582)\end{array}$ & $\begin{array}{l}-1.190^{*} \\
(0.693)\end{array}$ & $\begin{array}{c}0.576 \\
(0.806)\end{array}$ & $\begin{array}{l}-0.761 \\
(0.838)\end{array}$ & $\begin{array}{l}-0.867 \\
(1.253)\end{array}$ & $\begin{array}{l}-1.781 \\
(1.161)\end{array}$ & $\begin{array}{l}-0.265 \\
(1.764)\end{array}$ \\
\hline Physicians with malpractice payments & $\begin{array}{c}0.102 \\
(0.239)\end{array}$ & $\begin{array}{l}-0.356 \\
(0.296)\end{array}$ & $\begin{array}{l}-0.285 \\
(0.474)\end{array}$ & $\begin{array}{l}0.0307 \\
(0.621)\end{array}$ & $\begin{array}{c}0.164 \\
(0.459)\end{array}$ & $\begin{array}{l}-1.096 \\
(0.846)\end{array}$ & $\begin{array}{l}-0.795 \\
(0.674)\end{array}$ & $\begin{array}{c}0.935 \\
(0.707)\end{array}$ \\
\hline $\begin{array}{l}\text { Physicians suffering adverse actions } \\
\text { (Lead variable) }\end{array}$ & $\begin{array}{l}-0.377 \\
(0.413)\end{array}$ & $\begin{array}{l}-0.607 \\
(0.657)\end{array}$ & $\begin{array}{l}-0.169 \\
(0.882)\end{array}$ & $\begin{array}{c}0.594 \\
(0.753)\end{array}$ & -- & -- & -- & -- \\
\hline $\begin{array}{l}\text { Physicians with malpractice payments } \\
\text { (Lead variable) }\end{array}$ & $\begin{array}{l}-0.195 \\
(0.305)\end{array}$ & $\begin{array}{c}-0.968^{* * *} \\
(0.280)\end{array}$ & $\begin{array}{c}0.253 \\
(0.537)\end{array}$ & $\begin{array}{c}0.210 \\
(0.738)\end{array}$ & -- & -- & -- & -- \\
\hline $\begin{array}{l}\text { Observations } \\
\text { Adjusted } R^{2}\end{array}$ & $\begin{array}{c}816 \\
0.977\end{array}$ & $\begin{array}{c}816 \\
0.960\end{array}$ & $\begin{array}{c}816 \\
0.991\end{array}$ & $\begin{array}{c}816 \\
0.856\end{array}$ & $\begin{array}{c}748 \\
0.979\end{array}$ & $\begin{array}{c}748 \\
0.960\end{array}$ & $\begin{array}{c}748 \\
0.991\end{array}$ & $\begin{array}{c}748 \\
0.842\end{array}$ \\
\hline
\end{tabular}

